\title{
Spinoza's affective aesthetics: Art and architecture from the viewpoint of life
}

There is a peculiar aesthetic undercurrent traversing Baruch Spinoza's philosophy, harbouring untapped potentials and far-reaching implications for contemporary discussions on aesthetics. ${ }^{1}$ The relationship between aesthetics and Spinoza's philosophy, however, has been nothing but a huge missed encounter, resulting in the publication of only a few books and a handful of articles for more than three and a half centuries. ${ }^{2}$ This begs the question: is there, despite our persistent negligence, much more to the relationship of Spinoza and aesthetics than first meets the eye? I will argue that there might be. For once Spinoza's philosophy as a whole, ranging from his philosophical and political treatises to his private letters and unfinished manuscripts, is read between the lines, latent seeds of a peculiar aesthetic theory become visible-an aesthetic theory that moves beyond subjective and objective approaches that have come to dominate the field, and rather grounds itself on affective interactions and morphogenetic processes. That is, although Spinoza did not work on an independent theory of art and architecture built upon conventional aesthetic values, he developed, and grounded his philosophy on, a highly elaborate logic of affective operations, from which all aesthetic interactions immanently arise, including creative and experiential activities of art and architecture. A subterranean journey through Spinoza's affective aesthetics constitutes the subject matter of this paper, which interweaves subtle aesthetic hints buried deep within his philosophical archive, while unfolding relevant ramifications of these promising discoveries in relation to confluent artistic and architectural approaches for the current aesthetic discourse. $^{3}$

\section{Implicating affectivities}

In Spinoza's philosophy, modalities of existence (modus)-whether humans, animals, artworks, or architectural constructs-are all constituted by an immanent process of substantial individuation, which gives them their singular capacities, potencies, and rhythms. So, morphogenetic individuation of artistic and architectural modalities, that is, their coming into being, begins with a process of implication-as in plicating inwards, as in enfolding substantial forces of life. This is the initial voyage when artists and architects encounter an affective continuum beneath everyday forms, confront constitutive forces underlying 
extensive environments, and expose themselves to this chaotic dimension, to this turbulent undercurrent. In Spinoza's terminology, this process deals with substantial affectivities (substantiae affectiones), that is, how substantial forces of life (Being) are translated into everyday forms and events (beings) (E1D5). ${ }^{4}$ What is peculiar to Spinoza's approach is that formative potencies of cosmos (Natura naturans) are immanent to their formed expressions (Natura naturata) (E1P29S, $\mathrm{KV}$ 1.8-9). Which is to say, substantial affectivities that individuate everyday modalities are not situated above or beyond cosmos, do not transcend individual artworks or architectural buildings, but subsist in each and every process of individuation, like magmatic flows underlying tectonic mountains (KV 2.26, TP 2.2). Cézanne, who obsessively painted Mont Sainte-Victoire again and again in a series of oil paintings for more than twenty years at the turn of the twentieth century, shares Spinoza's morphogenetic concern, when he defines his obsession in this mountain as follows: "Look at Sainte-Victoire there. What élan... These masses were made of fire, and fire is in them still" (quoted in Gasquet, 1991: 8283). This is the aesthetic vision that accompanies each process of implication, the vision that does not only see a mountain's extensive contours, colours, and forms, but more importantly, recognises what caused that mountain to be, and what still flows beneath its unbending posture.

At the beginning of each aesthetic implication, an encounter takes place; artists and architects come across substantial affectivities or tangled forces of life. This encounter is not initiated by a brush, a pen, or an instrument; it is anterior to the first sketch, the first line, the first melody. What initiates it, rather, is an overwhelming confrontation with formative forces before they have assumed their actual forms. Yet why is this confrontation overwhelming? For it does not take place in zones of comfort, but in underground passages. For it does not rely on ready-made experiences of actual forms, but grounds itself on elusive experiences of substantial affectivities. In conceptual confluence with Spinoza, Olga Rozanova, the early twentieth-century abstract painter and theorist, explains this initial process elegantly: "How does the world reveal itself to us? How does our soul reflect the world? In order to reflect, it is necessary to perceive.... The artist's primary aspiration to create arises from this confrontation with nature" (1976: 103). And László Moholy-Nagy, the Bauhaus artist and architect, shares this intuitive trajectory, when he argues that architecture is not construction of buildings "from visible, measurable, and well-proportioned volumes;" rather, "real spatial experience rests...on the often invisible play of forces," that is, "space creation is an interweaving of the parts of space, which are anchored, for the most part, in clearly traceable relations extending in all directions as a fluctuating play of forces," rendering architecture "the medium of space-creating relations" (1947: 62). Does not Moholy-Nagy refer to what Spinoza calls substantial affectivities and formative forces of life, when he talks about "fluctuating play of forces" and "space-creating relations" in architecture? In a way, he does. For artists and architects are peculiar personae who find their own way to dive deep and witness subterranean affectivities beneath extensive landscapes and final forms, who endure extreme pressures and come back up from the fiery depths, with ringing eardrums, bloodshot eyes, and singular sears of their own. Yet it is also important to recognize that aesthetic implication is not a unilateral process, in which all forms of agency are consolidated within artists, architects, namely, within conventional subjects. For affectivities also express their presence in this encounter as formative events, as play of forces surrounding singularities of attraction and 
bifurcation. Affectivities strike artists and architects, not with their beauty or ugliness, but with their magnitude, radiance, and potence. And the humble role of artists and architects at this initial stage is nothing but to take notice, to affirm that aesthetic production does not begin with their subjective invention, but with a laborious discovery of substantial forces of life.

But on its own, an encounter with substantial affectivities means nothing, if it is not supplemented with a selective gesture. Despite its onto-epistemological focus, Spinoza called his magnum opus the Ethics, for what interested him was to make conceivable new ways of being and thinking, insofar as this conception makes way for a new ethos of surfing and curating one's own encounters in life. This means, at its core, Ethics is an exploration about how to harness substantial affectivities from everyday encounters, and select empowering compositions over weakening ones (E4Pref). This is Spinoza's ethico-aesthetic journey, in which the art of living and the life of art tend to become two expressions of one and the same reality. ${ }^{5}$ In other words, Spinoza's ethics of curating one's own life runs parallel to his aesthetics of curating the life of artistic and architectural modalities. But how does this curation, this selective gesture function? Once artists and architects come to notice substantial affectivities, they start supplementing their discovery with activities of vigilance and selection; they recognize different levels of magnitude and luminescence, capture them according to their radiance, enfold them according to their intensities, and channel them according to their potence (potentia) towards the genesis of their aesthetic production. ${ }^{6}$ Paul Klee, the modernist abstract painter, addresses a shared problem with Spinoza, when he defines this relationship as follows: "Our pounding heart drives us down, deep down to the source of all," but "what springs from this source...must be taken seriously only if it unites with the proper creative means to form a work of art" (Klee, 1966: 51). Subterranean encounters are incorporated into aesthetic productions only if they can be captured via creative selections. And for this reason, artists and architects capture topological curvatures underlying topographical landscapes; they take in subsisting forces of life; they channel radiant affectivities to pass through their alembic. All to prepare the generative conditions of their artwork-in-the-making. All to affirm the blending of the art of living and the life of art.

But who are these artists; who are these architects? Are they autonomous subjects or privileged authors, who command substantial affectivities from above, and create aesthetic artifacts with their omnipotent will? They are not, in Spinoza's aesthetics. For Spinoza argues that individuals, whether artists or architects, are not discrete, self-contained subjects, but entangled modalities that expand and contract via dynamic interactions within a distributed network of affective agencies. That is, if two or more modalities come to share compatible rhythms of existence, they might as well constitute a novel collective modality with emergent capacities of its own (E2P13Def). This means that an artist or an architect is never a solitary subject, but an enmeshed multiplicity, made of human bodies and minds, painting brushes and drawing pens, canvases and blueprints, artist studios and architectural offices, cultural inputs and economic exchanges, and all the common habits, specific discourses, and singular techniques emerging out of these interactions. Spinoza's philosophy neither endows aesthetic authors sacred roles and transcendent thrones, nor professes the death of the author by reactively rushing to the opposite pole, but presents nuanced ways of distributing agency and authorship within dynamic milieus.7 This conception implies 
that the author of an aesthetic production is not a human subject; it is not an entity, but an affective activity: a distributed network of aesthetic agencies and substantial affectivities, an entangled event evolving through the interaction of artists, architects, and all the actors that come to affect and be affected by this creative process. From Spinoza's peculiar lens, all modalities are aesthetic authors, albeit with different capabilities.

\section{Complicating affections}

As substantial affectivities are implicated into aesthetic production, another process emerges en route, a process of complication-as in plicating together, as in folding affectivities into complex compositions. In Spinoza's terminology, this process deals with modal affections (affectio). Modal affections are trans-individual encounters, in which the activity of an affecting modality, an external cause, is enveloped by and transcribed in the affected modality as an affective trace (E2P16). During this process, artists and architects complicate substantial affectivities by expressing them via modal affections. Through their creative exchange with canvases, constructs, and rhythms in the making, they orchestrate artistic sensations, architectural formations, and musical compositions. This is the stage of transmuting subterranean forces into terrestrial relations, the stage of expressing topological dynamics via topographical gestures, the stage of going back and forth between immaterial relations and material expressions.

At this stage, artists and architects transform the vitality of their initial encounters into aesthetic affections expressible within their specific medium. Yet there is a danger here, the danger of complicating via reduction rather than contraction. If the vitality of substantial affectivities is reduced while being translated into lines and colours, into sounds and rhythms, into forms and materials, then the artwork suffers, loses its intensity, becomes weakened. Reduction comes in many guises, diluting the intensity of aesthetic production. Imitative techniques may reduce artworks to derivative copies; symbolic representations may subordinate them into carriers of meanings external to their mode of existence; seductive clichés may curb their exuberance by channelling them towards paths already taken. According to Spinoza, moving beyond inadequate comprehension and reduction can only be attained via contemplating substantial affectivities, immanently, by contracting and expressing them in modal affections (E5P36). Artists and architects always run the risk of limiting substantial forces of life with weakening transformations, whereas their primary pursuit is to contract affectivities without depriving them of their singular intensity. John Cage, the experimental composer and music theorist, shares this insight of expressive contraction, as he argues that the musician's role is to "give up the desire to control sound," so as to "set about discovering means to let sounds be themselves rather than vehicles for man-made theories or expressions of human sentiments," which is an affirmation of sounds in their substantial intensity, and hence, "an affirmation of life" (Cage, 1961: 10-12). This is the latent ethos underlying processes of complication from the viewpoint of Spinoza's aesthetics: an affective transformation that, rather than reducing and subjugating life forces, affirms and contracts them.

During aesthetic complication, contracting and transforming substantial affectivities run parallel to experiments in constructing and composing modal affections. Composing modal affections on a specific artistic medium is the 
moment when the infinite speed of substantial affectivities finds a characteristic rhythm in finitude. Only by framing an acquired portion of chaos, by marking a partial multiplicity of substantial affectivities, works of art and architecture can contract the infinite, immanently, in a finite composition. This composition amounts to an aesthetic artefact's singular potence, characteristic rhythm, or conatus in Spinoza's words, which constitutes its mode of existence, affective capacities, and what its body can and cannot do in everyday relations (E2P13, E3P6-7). Artists and architects compose artworks and architectural constructs by way of framing their web of affective interactions. During this act of framing, however, a new danger arises, the danger of assuming the frame of composition an absolute limit that confines affections, rather than a permeable interface that catalyses contracted forces to open themselves up from within. For Spinoza, the characteristic rhythm or conative potence of an individual modality does not amount to, as is sometimes interpreted, an inward-looking mechanism foregrounding self-preservation and conservative autonomy. Rather, conative potence means the capability of an individual modality to open itself up to outside forces, affect and be affected by its environment, endure internal fluctuations and surf external oscillations, while at the same time acting and persisting in its own dynamic mode of being. ${ }^{8}$ Spinoza's memorable remark, that "nobody as yet has determined the limits of the body's capabilities: that is, nobody as yet has learned from experience what the body can and cannot do" can be interpreted, not only as a frontal attack against mental supremacy over bodily experience, but also as a novel way of envisioning bodily capabilities in affective and conative terms (E3P2S). We cannot know what the body of an aesthetic artefact can and cannot do, because its infinite capacities are actualized in finitude only through affective interactions with other bodies. Accordingly, an individual artwork or architectural construct cannot be limited with pre-given properties or reduced to fixed modes of behaviour-despite how much effort goes into these activities of limiting and fixing-because its capacities, tendencies, and affects will unfold only through trans-individual interactions on the fly. This means that each interaction with a work of art or architecture harbours the potential to unravel emergent capabilities beyond our initial predictions. Cedric Price, the eccentric architect of postwar England, addresses a shared problem with Spinoza, when he argues for "calculated uncertainty" in architecture, which means affirming and augmenting affective openness of spatial interactions, rather than limiting and controlling them. ${ }^{9}$ Calculated, because there is, indeed, a finite frame of composition. Yet what is calculated is uncertainty; what is composed is openness of affective interactions; what is pursued is rendering open-ended relations as generative and empowering as possible. For Spinoza, this affective experimentation constitutes our ethico-aesthetic journey in life: pushing the limits of our power always to new heights, opening up to as many affective relations as possible, and rendering these affections, to the best of our capability, empowering interactions for all the parties involved (E5P39-40).

The agency of an artwork-in-the-making makes itself felt to its artist the most during the process of complication. For an artwork is not a passive surface that registers the transcendent imposition of an artist's will, nor is an architectural construct a neutral container shaped by the autarchic order of an architect's pre-conceived plan. At every turn during the process of composition, an artwork-in-the-making renders unforeseen trajectories visible, develops deflecting resistances to certain approaches, reveals enticing tendencies for certain others. 
Francis Bacon, the painter of affectively charged raw imagery, argues that each painting "has a life completely of its own," and adds: "In the way I work, I don't in fact know very often, what the paint will do, and it does many things, which are very much better, than I could make it do" (Sylvester, 1987: 17). This gesture reminds us, once again, that aesthetic production is a developmental field charged with a myriad of intersecting agencies. And in this sense, Spinoza's ontology is pan-affective in composition, acknowledging the agency of each and every modality and affirming their equal share in existing, acting, affecting, and making a difference. This means artworks or architectural constructs are no longer devoid of agency; no longer mere reflections of cultural conventions; no longer mere receptacles mirroring their creators' subjective intentions. From Spinoza's aesthetic lens, artworks and architectural modalities are all singularly "alive, albeit in different degrees" (E2P13S).

\section{Explicating affects}

As modal affections are complicated, yet another process of aesthetic production emerges, the process of explication-as in plicating outwards, as in unfolding. This is the time when artworks and architectural constructs stand up on their own, present new sensations in expanded magnitude, and turn life back in on itself. In Spinoza's lexicon, aesthetic explication deals with affects (affectus). Affects translate modal affections, or affective traces of external causes, into a passage of power, into a modification of one's existence (E3D3). That is, affects are empowering or weakening transitions that result from modal encounters; they are what come to traverse interacting parties during the expressive unpacking of aesthetic experience. At this crucial point, we need to be careful not to confuse affects with feelings or emotions in the conventional sense of these terms. Rather, affects are unfolded expressions and explicated intensities of life penetrating our bodies and minds, which we only subsequently translate in the form of feelings. Affects are immanent modifications in our modes of being and acting, as we come face to face with a painting that overwhelms us, with a musical piece that takes us over, with a literary text that cracks our skull open, with an architectural building that astounds us.

Explication process begins, as soon as aesthetic artefacts come to attain their singular modes of existence. A painting comes to life, an architectural construct emerges into space, with complicated affections composed into lines and colours or forms and materials, as these artefacts start unfolding substantial affectivities enveloped in their newly constituted body through affects and sensations. As works of art and architecture come to interact with their audience, with us, a myriad of affections surge forward, a selection of which infiltrate our body and mind, affecting us, altering our power of existence, modifying our rhythm of life. This is how activities of affecting and being affected bring together processes of aesthetic production and aesthetic reception. Once we come face to face with aesthetic artefacts that perform an intensive explication, we witness an unfamiliar affect taking hold of our body, sending shock waves through our senses, twisting our nerves from within, showing us a sudden flash of what lies beneath. What is curious about this affective impact is that it is not limited to a single moment. Affects have their untimely dimension of their own; artworks and architectural constructs produce ever-changing affects at different times, in different places, in interaction with different individual and collective modalities (E4P9-10). This 
means that once works of art and architecture come to life, they no longer rely on their initial producers or immediate audience for their indefinite existence. From then on, they continue to express and unfold ever new affects. Artworks and architectural constructs are monuments, neither to their conceivers, nor to their perceivers, but to affective activity of life itself.

During aesthetic explication, the frame thrown over substantial affectivities is deframed once again; artworks and architectural constructs present their affective potence back to excessive forces of life; aesthetic interaction blends into life expressing and expanding its own affective repertoire. In Spinoza's words, auto-affectivity of life by way of modal explication is called beatitude (beatitudo) (E5P35-36). Beatitude has nothing to do with beauty in its conventional sense, as beatitude does not emerge from subjective judgements or objective qualities as beauty is believed to do (Ep. 54). Rather, beatitude is an affective procedure; it is the expression of explicated affects becoming one with their substantial affectivities; the journey of infinite multiplicities passing through finite modalities and reaching back to their substantial infinity. Artworks and architectural constructs participate in beatitude, in ecstatic expansion of life, insofar as they render sensible affectivities hitherto insensible, make visible forces previously invisible, make experienceable spatial relations that were formerly inexperienceable. With each explication of unforeseen affects, and sensations unheard of in their emergent intensity, life expands; works of art and architecture bring forth new ways of being; affective capacities of life are enriched. What aesthetic explication achieves, as Virginia Woolf the modernist writer subtly puts, is to "saturate every atom," that is, "to put practically everything in; yet to saturate," so as to return forces of life more vigorously back to life itself. ${ }^{10}$ This is the primary struggle of aesthetic production: how to harness imperceptible forces from substantial affectivities; how to extract modal affections from infinite fluctuations; how to convert these affections into intensified affects; how to compose these affects into aesthetic constructs; and how to make these constructs instigate affective journeys of beatitude, by expressing and intensifying the superabundance of life itself.

Implication of substantial affectivities, complication of modal affections, explication of expressive affects. ${ }^{11}$ Enduring an overwhelming exposure, constituting a complex composure, orchestrating an explosive release. For centuries now, scholars and commentators have pointed out that Spinoza does not pay attention to conventional aesthetics from the viewpoint of subjects or objects. ${ }^{12}$ And I am willing to grant that this is largely right. But what they have overlooked are latent seeds of a different aesthetic theory that moves not only beyond aesthetic judgements made by ready-made mental faculties of autonomous subjects, but also beyond aesthetic values found inherent to essential qualities of independent objects. Spinoza's aesthetic theory, rather, grounds itself on affective interactions immanent to and distributed within the interlacing of substantial and modal fields, which includes the agencies of both subject-based and object-based actors, yet is irreducible to one, or the other, or even both together. This is an aesthetic theory grounded on what goes in-between dimensions, processes, agencies, and milieus; an aesthetic theory of relationality, interactivity, and affectivity. Spinoza's philosophy potentiates affective aesthetics, not from the viewpoint of subjects or objects, but, in his subtle words, sub specie aeternitatis; that is, aesthetics from the viewpoint of life (E4P38, E5P29-36). ${ }^{13}$ 


\section{REFERENCES}

Barthes, R. (1977). The death of the author. In, Image, music, text (S. Heath, Trans.) (pp. 142-149). London, UK: Fontana.

Benjamin, W. (1970). The author as producer. New Left Review, (62), 83-96.

Boethius. (2008). The consolation of philosophy. Cambridge, MA: Harvard University Press.

Boscherini, E. G. (1970). Lexicon spinozanum. Hague, Netherlands: Nijhoff.

Cage, J. (1961). Silence: Lectures and writings. Middletown, Conn: Wesleyan University Press.

Certeau, M. d. (1988). The practice of everyday life (S. Rendall, Trans.). Berkeley, CA: University of California Press.

Cusa, N. (2001). De docta ignorantia. In J. Hopkins (Ed.). Complete philosophical and theological treatises of Nicholas of Cusa, vol.1 (pp. 1-160). Minneapolis, MN: The Arthur J. Banning Press.

Deleuze, G. (1988). Spinoza: Practical philosophy (R. Hurley, Trans.). San Francisco, CA: City Lights Books.

Deleuze, G. (1990). Expressionism in philosophy: Spinoza (M. Joughin, Trans.). New York, NY: Zone Books.

Deleuze, G., \& Guattari, F. (1994). What is philosophy? New York, NY: Columbia University Press.
Foucault, M. (1984). What is an author? In P. Rabinow (Ed.), Foucault reader (pp. 101-121). New York, NY: Pantheon.

Gasquet, J. (1991). Joachim Gasquet's Cézanne: A memoir with conversations. London, UK: Thames \& Hudson

Gatens, M. (2015). Spinoza on goodness and beauty and the prophet and the artist. European Journal of Philosophy, 23(1), 1-16.

Klee, P. (1966). Paul Klee on modern art. London, UK: Faber and Faber.

Lord, B. (Ed.) (2015). Spinoza beyond philosophy. Edinburgh, UK: Edinburgh University Press.

Lord, B. (Ed.) (2018). Spinoza's philosophy of ratio. Edinburgh, UK: Edinburgh University Press.

Mignini, F. (1981). Ars imaginandi: Apparenza e rappresentazione in Spinoza. Napoli: Edizioni Scientifiche Italiane.

Moholy-Nagy, L. (1947). The new vision and abstract of an artist. New York, NY: Wittenborn, Schultz.

Morrison, J. (1989). Why Spinoza had no aesthetics. The Journal of Aesthetics and Art Criticism, 47(4), 359-365.

Plotinus. (1989). Enneads.

Cambridge: Harvard University

Press.

Price, C., \& Littlewood, J. (1968).

The Fun Palace. The Drama

Review: TDR, 12(3), 127-134.

Rice, L. (1996). Spinoza's relativistic aesthetics. Tijdschrift voor Filosofie, 58(3), 476-489.

Rozanova, O. (1976). The bases of the new creation (1913). In J. E. Bowlt (Ed.), Russian art of the avant-garde: Theory and criticism 1902-1934 (pp. 102-112). New York, NY: Viking Press.

Schlerath, F. (1920). Spinoza und die Kunst. Münster: Hellerau bei Dresden.

Spinoza, B. (1985). The collected works of Spinoza (E. Curley,

Trans. E. Curley Ed. Vol. I).

Princeton, NJ: Princeton

University Press.

Spinoza, B. (2002). Spinoza: Complete works (M. L. Morgan Ed.). Indianapolis, IND: Hackett.

Spinoza, B., Curley, E. (Ed.). The collected works of Spinoza, vol. II (E. Curley, Trans.).
Sylvester, D. (1987). The brutality of fact: Interviews with Francis Bacon. London, UK: Thames \& Hudson.

Wolfson, H. A. (1969). The philosophy of Spinoza: Unfolding the latent processes of his reasoning (Vol. II). New York, NY: Schocken.

Woolf, V., Bell, A. O. (Ed.), 1980). The diary of Virginia Woolf, vol.3 (A. O. Bell Ed.). London, UK: Hogarth Press.

\section{ENDNOTES}

1 For English translations, I will use, and modify as necessary, the works of Samuel Shirley and Edwin Curley (Spinoza, 2002) (Spinoza, 1985, 2016), while referring to Lexicon Spinozanum by Boscherini for close reading of Latin terms (Boscherini, 1970).

2 For the limited scholarship on Spinoza's aesthetics, see, for starters: Schlerath (1920), Mignini (1981), Rice (1996), and Gatens (2015). See also the chapters on art and architecture in Beth Lord's edited books (2015 and 2018). Finally, Deleuze's peculiar aesthetic theory that operates via dual conceptions of percepts and affects (as in What is philosophy? 1994) or affections and affects (in his books on Spinoza, 1988 and 1990) can be deemed to largely flourish on Spinoza's affective grounds (while partially drawing from Nietzschean aesthetics, phenomenological trajectories like that of Maldiney, and his own singular tendencies). So, although Deleuze already connected certain dots and laid some of the groundwork for unpacking Spinoza's aesthetics for which I am grateful, what I construct in this paper, in the form of a tripartite affective system (implicating substantial affectivities, complicating affections, and explicating affects) is not based on Deleuze's dual constructions or any other previous scholarship on Spinoza's aesthetics (Deleuze \& Guattari, 1994). 
3 For the sake of a concise introduction to Spinoza's aesthetics, this paper focuses less on operational singularity of each aesthetic field (albeit implicitly laying the groundwork for this future analysis), and more on how art and architecture constitute a single continuum when it comes to affective processes of aesthetic construction and perception.

4 In E1D5 Spinoza says: "By modality, I mean substantial affectivities [substantiae affectiones], or that which exists in, and is conceived through, something other than itself." This notion, substantiae affectiones, is highly overlooked in Spinoza scholarship: it is usually translated either as "modifications of substance" (as in Elwes), or "affections of substance" (as in Curley and Shirley), and reduced to being equivalent to modalities. Yet, while trying to establish the primary distinction between substance and modalities, Spinoza is making a further conceptual gesture here. $\mathrm{He}$ defines substantial affectivities not as modalities themselves in the modal dimension, but as the self-causation of substance [causa sui], as expressed in the modal dimension. That is, substantial affectivities are substance affecting itself, which also equates, by way of immanent causation, to modalities. So, substantial affectivities as selfcausation and self-affectivity of substance (1), is formally distinct from yet immanently expressed by and as modal existence (2). Hence, developing substantial affectivity as a full-fledged concept grounded on this subtle distinction promises interesting insights into Spinoza's latent aesthetics. For this reason, I am translating substantiae affectiones, as substantial affectivities deliberately, for "affections of substance," "modifications of substance," and "substantial affections" can be very confusing to readers who are not well versed in Spinoza's philosophy, and might be easily mixed up with "modal affections," which refer to efficient causes and inter-individual relations, as will be defined in the next section. Therefore, distinguishing substantial affectivities from modal affections is a task as crucial as distinguishing modal affections from affects. By doing so, we arrive at the curious trilogy of affectivities, affections, and affects.

5 To see the development of this argument about the art of living (ars vivendi) being Spinoza's aesthetic motor, see Gatens (2015) and Mignini (1981).

6 Spinoza concept of potence (potentia) corresponds to the definition of a modality by what it can do, or set of potentialities that define an entity's capability of action and modification (potentia agendi, or vis existendi).

7 For the modern evolution of discussions on authorship, see for starters: Benjamin (1970), Barthes (1977), Foucault (1984), and Certeau (1988).

8 See Wolfson for how Spinoza expands the meaning of conatus to all human and nonhuman modalities while previously, from Stoicism to Hobbes, it was only reserved for humans and animals (Wolfson, 1969: 195-201). And see Deleuze for an interpretation that does justice to Spinoza's dynamic conception of conatus (Deleuze, 1990: 230-31; 1988: 98-102).

9 Cedric Price articulates his concept of calculated uncertainty at the concluding remarks of a speech called "Has the architectural profession a future?" that he gave at AA, London, in 1975: "What worries $m e$ is that our profession doesn't like the idea of uncertainty. If something is uncertain, they call it crisis and panic... Now unless architecture realizes that calculated uncertainty is one of the great generators of what it should be doing in the future, then I think the profession has no future. But I think, architecture has one. Thank you." To witness the epitome of Price's approach to architecture, see his Fun Palace project (1963-74), which explores how architecture can not only undergo, but also instigate constant change with the help of user potentiation and cybernetic intelligence (Price \& Littlewood, 1968).

10 This entry is from Woolf's diaries, dated "Wednesday, November 28th, 1928" (Woolf, 1980: 209-210). In his aesthetic discussions, Deleuze likes to often refer to this passage as well, as part of his idiosyncratic strategy of revealing how artists are as intuitive of affective operations as philosophers, albeit with unique sensitivities of their own.

11 The conceptual triad of implication-complicationexplication addresses the problems of ontological individuation and the relationship of Being and beings, which has a long history of evolution in Western philosophy before Spinoza radicalized it in his own work. The latent seeds of these concepts lie in the Neoplatonic problem of emanation of the One and participation of the many, developed by Plotinus, and published by his student Porphyry in Enneads (ca. 270). Following this trajectory, Boethius applied the terms comprehendere and complectiri to unity and eternity of Being in Consolation of Philosophy (De consolatione philosophiae, 523 A.D.), which are in turn subordinately unfolded as plurality and temporality of beings. In the following centuries, Boethius's commentators developed his conceptual couple of complicatio-explicatio, culminating in the rigorous teachings of Ecole de Chartres in the twelfth century. Inheriting this conceptual mechanism of folding from the school of Chartres but channeling it away from emanation towards immanence, Nicholas of Cusa argued in Bk. II, Ch.3 of On learned ignorance (De docta ignorantia, 1440) that "God is the enfolding of all things in that all things are in him; and he is the unfolding of all things in that he is in all things." Finally, bringing together a variety of sources from Neoplatonism and Cartesianism to radical Abrahamic and Scholastic traditions, Spinoza pushed this relationship to its own limit by grounding it on absolute immanence. With Spinoza's radical gesture, which was most rigorously uncovered and developed by Gilles Deleuze, the successive and hierarchical emanation of Neoplatonism gave way to adequate expression and immediate co-presence of three movements: modal beings, while remaining in substance, implicate (imply, involve) and explicate (explain, express) substance, and substance, while remaining in itself, complicate (comprehend, contain) modal beings (TTP, $c h$.
4). By focusing on the conceptual triad of implication-complicationexplication, this paper argues that Spinoza's conception of ontological individuation runs parallel to his conception of aesthetic individuation. For more information on this conceptual triad, see Plotinus (1989), Boethius (2008), Cusa (2001), Deleuze (1988: 68-69).

12 See especially how Morrison (1989), based on his rationalist reading, goes as far as declaring that Spinoza cannot have an aesthetic theory, as he is not interested in subjective intentions and judgements.

13 Sub specie aeternitatis is usually translated in Spinoza scholarship as "from the viewpoint of eternity." What Spinoza means with this term, however, is to see things from the viewpoint of substantial forces of life, or which amounts to the same thing, from the viewpoint of how things are immanently generated, from the viewpoint of life. And by "life" here, in the title, and in the entire text, I follow Spinoza's definition from Metaphysical thoughts, in which he equates life both to conative potence of each modality and to the substantial continuity of God or Nature itself: "So we understand by life, the force through which things persevere in their own being," and "because that force is different from the things themselves, we say properly that things themselves have life," and hence: "So they speak best who call God life.... God is life, and is not distinguished from life...." (CM 2.6 ( G1:260). 